\title{
Gathering together: social capital, cultural capital and the value of cultural heritage in a digital age
}

\begin{abstract}
Cultural heritage is generally regarded as something of value - but it is valued in different ways by different communities. Here we explore the value of cultural heritage for rural Scottish communities and how it is generated through social and cultural capital. Using the idea of 'gathering', we consider the process of gathering historical archives, narratives and gathering places based on local knowledge. We draw upon a study of communities in the Outer Hebrides of Scotland, where a wellestablished cultural heritage tradition has developed and is continuing to do so with the adoption of various digital technologies. The paper argues that cultural heritage offers a real sense of cultural value for participants and communities for which digitisation offers both threats and opportunities. The paper adds to our understanding of locally generated cultural capital and the meaning of cultural value.
\end{abstract}

Keywords: cultural value, cultural capital, social capital, cultural heritage, historical associations, memory, digitisation, digital geography

\section{Introduction}

Rural areas such as those in the Outer Hebrides have strong place identities, formed through the reproduction of traditional cultural practices alongside contemporary influences such as digitisation. These identities are performed and constructed through a repertoire of knowledge, histories and customs (Waterton \& Smith, 2010). We could see this as a form of locally generated cultural capital enabling the representation of community life through the stories that are told about it. Communitybased initiatives play an important role in the production of local cultural heritage and this case study is based upon the Comainn Eachdraidh (CE), the Gaelic historical associations found throughout the Western Isles and Highlands of Scotland. The CE represents a distinctive example of how value is generated through cultural and social activity which is then circulated within the community in order to maintain a historical sense of place (Massey, 1994). It can help us to better understand the interlinkages between different forms of capital and their relationship to cultural value.

Cultural capital is generated from cultural heritage through the creation of cultural value. Whilst cultural capital and cultural value are usually associated with civilizational-level knowledge or artefacts, this paper will demonstrate how these factors are generated at a local level through community activities and shared understandings that are "bottom up" and even oppositional to mainstream hegemonic culture. The contribution of this paper is to understand how cultural value is generated through community social relationships and day-to-day participation (Miles and Ebrey2017, Skeggs 2014).

The key to developing cultural value in rural areas through cultural heritage is the process of gathering historical materials and the expertise that this builds among community members. Gathering is therefore used as a catch-all term for the variety of processes that go into the construction of community archives, whether this be the sifting through a loft full of photographs, the mapping of historical of landscapes, the ordering of neatly boxed files in a room or the creation of digital files on a web based archive. They all represent forms of gathering that require collaboration and communication between community members, creating a sense of collective 
purpose and identity. Therefore, gathering can also refer to the bringing together of a community of people as a way of generating value (Beel et al. 2017). It further creates gathering places, which we shall argue can be both material and virtual. The paper therefore, in the latter sections considers that relationship between the material and virtual to think through the digital geographies (Ash, Kitchin, \& Leszczynski, 2016) of gathering heritage collections via new methods that sit alongside existing practices (Beel et al. 2015). In doing this, the paper suggests that in these early stages of digitisation mirror aspects of the 'digital turn' in geography as community groups learn to wrestle with the opportunities and tensions that new practices create.

The paper divides into four main sections: firstly, it considers theoretical links between cultural capital, social capital with cultural value and the role of cultural heritage work in making these links. Secondly, it will introduce the case study communities. Thirdly, the paper will highlight how heritage collection and preservation builds linkages across communities by generating locally based social and cultural capital through the idea of gathering - archives, narratives and places. Finally we shall consider some of the broader implications of these insights.

\section{Cultural capital, social capital and cultural value}

Cultural capital is the set of attributes, dispositions and 'taste' that is valued in a given society (Bourdieu 1984) and reproduces elite positions through the artefacts and knowledge that embody cultural goods. Bourdieu (1986:243-244) divided the concept of cultural capital into three different elements; embodied, the sense that such capital is passively acquired over time, for example due to family upbringing; objectified, which relates to the acquisition but also the knowledge of objects either for profit or show, an example being the knowledge and ability to purchase an expensive painting; and, institutionalised, where some form of institutional recognition is given for achievement, often closely linked to educational success. Hence for Bourdieu acquisition of these key facets gives power to an individual to act and to join specific fields.

Whilst Bourdieu was concerned with society as a whole, we can also consider the generation of cultural capital within specific locations where the valuing of particular artefacts, expertise or knowledge has more specific meanings. Bourdieu was concerned with cultural capital mainly as a form of inclusion/exclusion in hierarchal social relations. However, in a local context, the building of knowledge around particular themes can also be a way of demonstrating an alternative cultural capital, that as will be shown represents: an embodied relationship to the history of landscape and community; an objectified relationship to the ephemera of the Gaelic island tradition in which value is placed in potentially forgotten objects by the different communities, and; an institutional approach by the ways in which Island communities have sought to formalise their links to history heritage through forming social structures such as the CE movement. In other words, we stand Bourdieu's concept of cultural capital on its head to show how this is generated by minority communities from below rather than by hegemonic authority from above. In order for this generation of heritage from below to be generated and shared, it relies upon social capital something that is strong on the Outer Hebrides where participation in associational life has traditionally been high.

Cultural capital is circulated and reproduced through social capital. Social capital refers to the collective 'value' added to society from social networks and participation in civic associations such as CE (Putnam 2000). Like cultural value, social capital is therefore intangible in itself but can be understood through the various ways in which it is generated. For Bourdieu social capital is the value embedded in social networks that can be realised by individuals to their advantage (Bourdieu 1983, Bourdieu, Wacquant 1992). Social capital is the sum of resources, actual or virtual, that accrue to an 
individual or a group by virtue of possessing a durable network of more or less institutionalised relationships of mutual acquaintance and recognition (Bourdieu and Wacquant, 1992:119). Whilst Putnam (2000) feared that social capital was in decline due to changes in residential, work and leisure patterns, in the Outer Hebrides it was extraordinarily strong and growing, partly as a result of intense interest in cultural heritage. Both social and cultural capital can help to generate cultural value to which we now turn.

'Cultural value' as a concept is both intuitively understandable but at the same time empirically difficult to tie down (O'Brian 2010). One use of the term is for cultural organisations to borrow economic vocabulary to justify expenditure on culture (Smith 2010) and there is a real issue around how to value non-market goods (O'Brien, 2010) and the worth they bring to people. This is related to an uncomfortable relationship between 'intrinsic' and 'instrumental' values of culture (Holden 2006, Orr 2008, Graeber 2001) or what Skeggs has termed 'different value practices' (Skeggs 2014). Who defines and sets cultural value also, to a certain extent, defines what that 'value' is, hence both are often underpinned by political, economic and social factors for the communities themselves.

Cultural value, like cultural capital, is usually taken to refer to hegemonic regimes. It is about what a civilization values in 'high' cultural heritage and is therefore a way of creating hierarchies of value which reflect and reproduce the social hierarchies prevalent in a society - or more broadly, a civilisation. The value of a cultural good can be assessed by what people are prepared to pay for it. For example, a Leonardo da Vinci painting sold for $\$ 450$ million at auction recently represents the value attributed to the traditional cannon of cultural heritage. Yet this value is not wholly 'objective'. It is generated by the cultural capital of elite knowledge and by communities of interest and expertise - by social capital - that are reflected in this auction price. Similarly, a recipe book based on a grandmother's methods for managing to produce meals from the limited resources provided on a Scottish island might not have sold at Christie's but it can be of immense value to the community from which it originated. The kind of cultural capital embodied in this heritage artefact is realised in its value to the community in question. Whilst the first type of cultural value is universally transmitted, the second type is highly localised.

Here we aim to think about the ways in which cultural value is constitutive to individuals and communities and embedded in everyday cultural practices. We frame cultural value, as the variety of ways in which individuals and communities undertake activities to express things that are of value to them. Historical associations create differing 'regimes of value' (Appadurai 1986) that create more 'bottom up' articulations of cultural heritage (see Robertson, 2012) rooted in local understanding and belonging. This process has had significant impacts upon the social formations that take place in these rural communities and offers specific ways of creating cultural value through heritage creation (King et al., 2016). This connects strongly within social and cultural geography with work upon memory and the variety of geographic spaces that have been shown to foster and shape practices of remembering (Mackenzie, 2010; Withers, 1996). Gathering acts as a practice of remembering and memory production (Nora, 1989). It is conducted both as individuals alone, in private or domestic spaces (Meah \& Jackson, 2016), as well as in groups in more 'formal' or public spaces (Alderman \& Inwood, 2013; Rose-Redwood, 2008). The project enabled the creation of a database of records, which could be cross-referenced and accessed openly based upon individuals, crofts, fishing boats or other reference points (Tait et al. 2013). This used semantic web technology, which in principal could link with other records and sources outside of the local community (for instance with national archives) enabling online searches and the construction of new information and narratives around local sources as they were connected in new ways both internally and externally. This therefore represents what Rose (2015) terms as the movement of cultural 'artefacts' into digital form and this 
paper seeks to consider the changing geographies created by such a transition to collective way of knowing (Elwood \& Mitchell, 2015). Central to this, as has been to various geographers interested in transference to digital technology (see Kinsley, 2010 and Wilson, 2012) is the work of Stiegler (2010) who frames this paper in addition to the more arbitrary notions of cultural value above. The paper revolves around the transmission of cultural memory between individuals, communities and then across digital technology. Stiegler is concerned with the 'externalization of knowledge', and the ways in which different 'technologies' externalize knowledge differently. In application of Stiegler's work Kinsley (2010) and Wilson (2012) do what Elwood and Mitchell (2015:150) state as:

They situate digital social and spatial media as 'technics' that, following Stiegler, externalize knowledge such that it can be transmitted across time and space. Within this framing, writing a letter, drawing, tweeting, or sharing a photo through Instagram are all technics that connect our knowledge and action in the present moment to knowledge and possible action in a future moment, and open the possibility of collective uptake of individual memory.

This means, there are implications as to how and why knowledge is transmitted. Thus, the transference from older analogue technologies held within place-based archives to the digitally networked web-based ones impacts upon how this data is created, reinterpreted in digital form, understood and appropriated by individuals and communities. This then redefines some of the socio-spatial relations that exist within, between and around these archives.

In following how such practices then move into digital forms of production, this reflects the approach by Ash et al (2016), who highlighted that within Geography itself the 'digital turn', has unfolded in tripartite form. They suggest that this can be viewed as 'geographies through the digital', the process of knowledge production that uses digital technology; 'geographies produced through the digital', the ways in which digital technology reshapes socio-spatial relations; and 'geographies of the digital', the relationships created within digital networks. In terms of this paper, we find these concepts useful as they reflect the 'digital turn' made by community history groups in presenting their place histories. Hence their activities as they move towards digital formats are geographically and historically 'through', 'produced' and most nascently 'of' the digital. It is therefore argued that digitisation provides new opportunities for cultural participation and the development of collective identities and that this is more than just a technical process of putting collections online, it reshapes the socio-spatial relations of the groups over time.

It is therefore argued that digitisation provides new opportunities for cultural participation as well as for transmission and that this development impacts upon the collective identities of those involved. This makes such activities more than just a technical process of putting collections online but an embodied form of memory transmission that has significant cultural value. Rose (2016) has highlighted that despite the often-negative potential impacts or threats created by new technologies, there can also be several positive, unrealised impacts too (Longhurst, 2013, 2016; Thompson \& Cupples, 2008) and this paper through its empirical materials will highlight these.

\section{Methodology}

In this paper we focus upon the Western Isles of Scotland where there has been a strong heritage movement going back several decades and based upon the distinctive understanding of history in this region and relating to the use of the Gaelic language. Where possible active participant observation was used. This allowed the researchers to experience, in a more flexible manner, the everyday happenings of the case studies (Cook 1997) by taking part in the work of the CE groups that encompassed 'the full experience of being in a place' (Kearns 2000). The participant observation 
carried out took place in multiple different sites (25 in total) in the Western Isles during the research period of November 2013 to April 2014 by one of the authors.

To complement this, 19 semi-structured interviews took place with CE members and relevant organisations over the same period of time. Interviews allowed questioning, in far greater detail the feelings, emotions, reactions and practices of individuals involved. As 'a conversation with a purpose' they enabled communication and questioning of respondents as they went about their activities (Eyles, Smith 1988).

This activity represented the culmination of work with the CE that began in 2010 with exploratory fieldwork and initial discussions. The researchers were involved in a large digital economy hub which emphasised the importance of working with practitioners to create digital solutions for their problems. Our contacts were with Hebridean Connections (see below) and together we created a programme to digitise the local heritage collections and to train local volunteers in how to use it. This work, initially funded by the Engineering and Physical Sciences Council of the UK was then supplemented by grants from various sources to the local historical associations themselves to enable them to employ outreach workers to implement the project.

Finally, we received a grant from the UK Arts and Humanities Research Council, which funded the work of one of the authors to carry out more intensive fieldwork on the Outer Hebrides in order to understand the context of these interventions and provided the material used in this paper.

The fieldwork involved participation in CE activities and meetings, immersion in the local places of gathering including cafes and museums and interaction with key community leaders and activists. Material here is based upon information collected from them as well as field notes and photographs taken during the research period.

Information was recycled back to communities through a number of talks and presentations which formed part of the impact of the project, which also enabled us to check and refine our analysis.

\section{The Comainn Eachdraidh movement and Hebridean Connections}

Cultural heritage has a strong role in the Western Isles, through the organisation of historical associations in every island or sub-region, to which almost all local people subscribe. Some of the islands have a singular CE (South Uist for example) whereas others have multiple CEs (such as Lewis). The CE represents a medium for the cultural transmission of meaning (McGuigan 2994) in order to present and preserve a 'way of life' (Williams 2010) that for Islanders is seen as fragile and under threat. The CE represent a strong set of associations that have developed over several decades and forms one of the most important civil society associations in this region. The CE Movement began in the 1970s, linked to the History Workshop movement (Samuel 1981) with a very specific political and cultural purpose: the collection and preservation of highland and island cultures, with particular reference to Gaelic. The first phase of the project took place from 1976 to 1982, beginning in Ness. It began with the key aim to create "an awareness of the cultural identity and community history as a means to boosting morale and promoting a discriminating understanding of the past and of its influence on the present" (Mackay, 1996). It is from this position that over the subsequent years, due to the popularity of the project, that new CE groups began in different areas of the Hebrides, the latest being the recent creation of Eriskay CE.

Today, twenty CE are currently active in the Outer Hebrides all of which are entirely independent of each other. Each group has its own members, committee and collections, and are dedicated to researching their own specific geographical areas. Figure 1 shows how these are distributed around the islands. The most active members and primarily those involved in this study are of an older age 
and (usually) retired but cross-generational participation does take place in a number of ways, often through the shared use of CE buildings. Both men and women participate in the various activities that they run and in these often sparsely populated and dispersed small settlements, they have a central role in functioning of Island life. Local CE associations have waxed and waned over the years with some becoming very active and others moribund and new ones often forming, reflecting shifts in local populations and key actors.

\section{*Insert Figure 1 Around here*}

The different groups collect a wide variety of materials relating to both physical objects, or what Bourdieu terms objectified cultural capital. These might include school log-books, individual collections of diaries, notes and photographs, personal objects, industrial objects, archaeological artefacts, newspaper cuttings, paintings, crofts, buildings, boats and gravestones. However, other aspects of cultural heritage are less tangible and could include oral histories and stories, genealogical knowledge, shielings, local place names, patronymics, Bárdachd (poetry), local dialects, Gaelic dialects, Gaelic terms and recipes. Some of these were collected and stored but others were part of the living cultural heritage of the community and were embodied in particular people or networks. The artefacts themselves represented "embodied cultural capital" in Bourdieu's terminology insofar as they had meaning for that particular community in terms of local knowledge. This reflects a form of vernacular heritage, which is embedded within its places of production (Edensor, Leslie, Millington, \& Rantisi, 2009; Muzaini, 2013). Like all community groups, they were teeming with micro-political relations both within each CE and in relation to each other. This reflects that although different CE groups have similar interests and follow similar narratives they do not form a hegemonic movement or represent a singular community interest.

A new dimension to cultural heritage has been the digitisation of resources, which enables them to be preserved, but also presented and connected in new ways. It enables a connection between local knowledge and more general access, since digital resources are available to people outside the community, including a large Scottish Diaspora from North America, Australia and New Zealand, with a keen interest in this heritage. In the case of the Outer Hebrides, this digitisation was achieved through an organisation called "Hebridean Connections". Hebridean Connections is a collaboration between 10 of the 20 active CE in the Western Isles. This highlights the earlier point with regards to the micro-politics of group relations, as Figure 1 shows, it loosely highlights a North/South split in participation which reflects some longer running historic tensions between differing islands and CEs. Hebridean Connections has provided training to local CEs in digitising resources and also a collective platform which could exhibit information on line and provide a way of searching for information about individuals, crofts or other things. It further provided links between the information held by different CE organisations enabling cross linkages of information to be made. For example if a person moved home or married someone in a different CE area, these connections could now be traced. This was of particular value to those outside the community, for example the Scottish Diaspora, who were interested in following these links or tracing family histories.

\section{Gathering heritage: building community archives}

The main work of the CE groups is still around the production and maintenance of their individual physical archives and the collecting of history and heritage related to their own areas. Archives such as those collected by CE are generated as an articulation of 'heritage from below' (Robertson 2012). They represent spaces of 'marginalised memory' (Cresswell 2011) by attempting to give a counterpoint to more top-down and mainstream articulations of history (Mason, Baveystock 2008). They in themselves represent 'mechanisms' or 'technologies' for preserving memory across 
spacetimes (Stiegler, 2010). As Stevens et al. (2010:68) suggest, their relevance and value extends well beyond the physical site of the archive itself, it is 'the active and on-going involvement in the source community in documenting and making accessible their history on their own terms' (Stevens, Flinn et al. 2010). This makes understanding the practice of archive production amongst volunteers central to comprehending their broader value as it produces both cultural capital in terms of local knowledge/expertise and social capital in terms of collective involvement (Beel et al. 2017).

The relevance of community heritage archives to understanding cultural value is due to the way in which volunteers in historical societies mobilise and build connections through historical narratives. This is revealed in the ways in which they reflect upon their desire to represent their histories and to tell the everyday stories about their communities. Hence, it is the political motivation to express an historical narrative collectively that reflects the interests of a particular place. This often sits against the more sweeping local state or nationalistic heritage claims that miss out the finer grained and every day social histories of place (Mason \& Baveystock, 2009). For Cresswell (2012:165), such community archives represent spaces of 'marginalised memory' that draw 'attention to the things people push to one side and ignore, the things that do not make it into official places of memory'. Such activities therefore enable the representation of community based on local knowledge.

This generation of heritage from below 'is both a means to and manifestation of counter hegemonic practises' (Robertson 2012:7) based upon the lives of ordinary people. Central to these arguments is place, identity and a notion of dwelling (Ingold 2000) that builds over time and reinforces each in relation to the heritage the communities wish to create. In the context of the Western Isles this further builds upon a relationship in the Gaelic communities between sense of place, identity and possession whereby 'attachments to place are intrinsic to identity, rather than to buildings or monuments' (Robertson 2009:154). The Gaelic language infuses names of places and the people who inhabited them with a rich sense of meaning, both past and present. This rich heritage was often lost in translations into English. For example the limited repertoire of people's names in English used by census recorders or by public administration fails to distinguish the diversity of lineages denoted by nicknames and patronymics. The communities on the Outer Hebrides had a strong sense of their histories being misread or mispresented by outsiders, especially those that did not understand Gaelic. This built on the sense of historical injury which grew out of dispossession through the Highland Clearances of the $18^{\text {th }}$ and $19^{\text {th }}$ Centuries when landlords evicted Gaelic communities from their land and the subsequent suppression of the language until the late twentieth century. In this sense it was a form of oppositional cultural capital embodied in the traditions and places from which it has emerged.

The key way in which the CE present a historical sense of place tied to the land is through documenting the crofts and the people who lived on those crofts, often connected genealogically to the current members. Crofting rights emerged from legislation at the end of the nineteenth century aiming to re-populate marginal land emptied through the clearances and emerged from a popular movement (Mackenzie 2013). Hence this local history, whilst referring to earlier periods, usually begins around the end of the nineteenth century when the crofts were created, even if it refers back to the historical traumas of a previous period. This relationship between land, people and place is what makes the CE so interesting and often so different to other historical societies throughout the UK; very few other places are able to represent such a lineage. It also makes a strong political statement with regards to land tenure, an exceptionally contentious issue in the Islands both in the past as now (Hunter 1976). In this setting, the archive stands as a statement of endurance, ingenuity 
and perseverance for the families that have maintained their connection to the land, and which has continued through previous generations. This longevity of knowledge for CE is particularly valuable to these communities as it shows their continued embeddedness in the landscape.

Hence, local knowledge enriches the experience of place and in part highlights why some of the CE activities of collection take place. This is in terms of wanting to 'know', in detail, about the place they are from and how that has produced the landscape in which they live. What may seem a simple observation to 'look out for' shows an attention to detail to observe and be in a landscape. This is a key part of how CE value local knowledge about place and expands into a series of other activities that attempt to codify space as 'known' as well as it being culturally significant. A number of CE have chosen to map out all the distinctive Gaelic place names which relate to agricultural land where sheep would have been previously kept by crofters. To a certain extent these names went out of use due changes in agricultural practices, but to re-map and re-claim them is to again symbolise the landscape in terms of the past practices of crofters and helps maintain their Gaelic names. These processes are bound within notions of dwelling (Rose 2012) in terms of a set of processes that attempt to mark and claim the landscape.

Although cultural capital in this sense embodied local knowledge, it is also linked to social capital in the way in which heritage activities and meetings of CE help to value and reproduce this knowledge. Despite this emphasis on traditional communities, in fact many of the residents of the Outer Hebrides are 'incomers', reflecting trends in retirement and counter-urbanisation, which can cause resentment (Jedrej, Nuttall 1996). Yet through participating in cultural heritage work and the CE, incoming members of the community are able to form links with the surrounding community, both social and symbolic. It helps them to establish themselves in the local landscape and participate in this embedded knowledge. Indeed the strong sense of community is one of the factors that attracts them there.

Hence, in Bourdieu's sense, embodied cultural capital was managed through the inter-generational transmission of knowledge, genealogies and names, whilst objectivised cultural capital was embodied in the archives and artefacts themselves. These forms of cultural capital were institutionalised through the $\mathrm{CE}$ itself, which also represented one of the main forms of social capital. However, in contrast to the kinds of elite or hegemonic cultural capital that Bourdieu was mainly concerned with, the forms of cultural capital described here were embedded in the history of a particular locality.

\section{Gathering narratives}

Although the croft, as a traditional peasant smallholding, is the backbone around which most CE base their collections this leads in turn to the production of broader village histories, helping to form a stronger sense of place identity. The process of developing these community archives is centred around social relationships and is the process by which 'value' is attributed by community members that are involved. The CE groups enjoyed the process of reminiscing as they sifted through these collections, such as remembering their past school days and those of others. This was one of the reasons why old photographs, rolls of honour (a record of those lost at war) and school records were particularly treasured. It was also the way in which the conversation moved to draw out the memories of older volunteers so that they could then be written up or drawn upon for others to gain a stronger sense of the history of the area. Thus, narratives play a central role in externalising cultural meaning to make it transmissible in different ways (Stiegler, 2010). This process is more than 
simply handing down objects from generation to generation as the narrative itself is the first kind of externalization that then allows following things to happen. Hence, the shift from oral narration to textual archive (which constitutes the primary work of CE movement to date) is the foundation upon which digitized content can be created this in turn allows a whole set of other things to happen (see Stiegler, 2010; Kitchin and Dodge, 2011; Wilson, 2011). Therefore, this means such process clearly contribute to something bigger, something more fundamental, that continues to lead to an on-going production of the history of place for North Lochs: if this did not happen, such memories and knowledge would be lost. The narratives also create meaning out of the collection of objects found in the museums (such as milk churns, old domestic equipment, spinning wheels and shepherd crooks) which in themselves have little intrinsic value, but whose value is created by the narratives which have meaning in that community due to their 'externalisation'. For example the spinning wheels were often passed down through female lines of descent, as the shepherd's crooks were through male ones. Hence by meeting and reminiscing in the CE groups, embodied cultural capital could be inscribed in the collection of artefacts and their meaning preserved.

The process itself, the shared experience of participating, collecting and listening with others; the sense of producing something of worth for the community and its ability to bring people together, contributed to a sense of wellbeing and cohesiveness:

I think the word in itself says that: 'community'; because it is bringing something together which is common to us all. We don't get together that much, as a community, as people here - as they used to in the past. And if you've got something like this and it will drag people together, then it's a good thing. We need something in our communities actually to keep the people coming together as a community and if we didn't do it, it would be just another bit that was lost. (Respondent 14)

However, it was also the way in which the community constructed itself. The non-inclusion of uncomfortable memories such as religious schism, divorce, crime and incest means that a wholly happy and cohesive vision of community could be constructed. Hence a representation of community cohesion was part of the way in which the communities constructed themselves (Wallace et al. 2015). It is also the way in which the groups define and decide what knowledge is valuable to them and what is not. This process, like in any cultural institution, reflects their practices, or what Hetherington refers to as the 'regime of curiosity', which is attuned to 'pick out' the things, objects and narratives that other collections or historians have missed, chosen to ignore or seen as irrelevant, but which are also selective in their representation(Hetherington 2006). Hence this history is no less 'true' than the larger academic narratives, but forms part of the social relations of the community itself. A large proportion of this reflects how, as has been mentioned, the CE groups want to develop their own sense of history and identity, which they collect and narrate (selectively) on their terms. This has, to date, been created collectively and resulted in vast repositories of materials for the different communities.

For CE members it is the importance of valuing 'things': objects, stories and genealogical knowledge that others might have missed, chosen not to keep or which have simply never been recorded. Hence this sense of historical loss was part of the motivation to record and collect:

Well if it's not recorded it will go, it will just be oral history and there has always been a tradition of oral history which is why there's a lot of things you know but you have no record of...it's just something you've always heard but it's never been written down anywhere and I think these things should be recorded. And I think they have as much 
value as written history, while they are still oral. I think some people denigrate oral history as something that doesn't have the same value because it's hearsay, in a way, and it doesn't - there's nothing to verify it but it's still extremely valuable I think, in local history. (Respondent 6)

The process of collecting is therefore a form of social memory (Nora 1989) that creates a repository of community knowledge which can then be used by others to learn about their history and heritage. The process therefore reflects a central ontological angst that the CE groups share and partly drives their activities. If they were not to collect this information, it would be lost:

I'm in my mid-seventies now so growing up, there was no television or even radio, a couple of people had radio so it was either playing outside or else in the taighean [ceilidh] and listening to the stories ... It was really to give it a proper status and start recording stuff because we were realising that the stories were being lost and it's only people like myself now, who is [recognised] as the older generation - I still feel, going looking for older people to record and then I realise, 'Well that's me!' But that's really how it started; trying to record as much as possible before any more is lost. (Respondent 2)

And we were given a sense that the oral tradition was beginning to break up. And I suppose a key driver was to get ... we had, for instance, we had people who had spent a lot of time in Patagonia, we had people who had come back from Australia and it wasn't one or two people going out, it was maybe fifteen, twenty men from the community going away to Patagonia, there was a real sense we had to get some information on that before these people passed over. And I think that was one of the key drivers. (Respondent 5)

The respondents above highlight how such community knowledge was previously passed on and how this has had to change due to ways in which people no longer gather or retain information as they had in the past. The archive therefore becomes the cultural repository for this knowledge and memory, acting as a point of reference for communities to trace back and gather their histories. Once recorded and documented it could become 'institutionalised social capital' and therefore preserved.

For the volunteers, the mixing of their own knowledge and remembering people, places, events and so forth in order to better organise the archive, gave great satisfaction. Evidently, the desire to comprehend personal and community histories and genealogies often acts as the 'spark' that draws people into being involved with CE:

I just, again, came to Comann Eachdraidh, I don't know how, it's so long ago I can't remember! I suppose I was always interested in my roots and I had an uncle who was very interested in genealogy and I suppose I just got into it that way and here I am, decades later and that's it: once you are in, you are in, you are hooked! Decades later and that's it. (Respondent 16).

In this way respondents help to create a representation of community. However, community is a contested concept (Mulgan 2015) and whilst cultural heritage helps to create a sense of historical continuity, it belies the fact that the population of these communities has changed over time with population decline followed by more recent counter-urbanisation. This has brought an influx of a retirement population, many of whom are not Gaelic speaking, but are nevertheless keen to belong. The loss of younger families is reflected in the availability of school houses for conversion to cultural heritage centres. The keen sense of nostalgia and potential loss that emerges in the interviews, perhaps reflects an awareness of a particular chapter of history and of the lives of residents, coming 
to an end. And yet the work of the CE has also helped to revitalise these small, remote communities as we shall now show.

\section{Gathering places}

An important factor that enabled the institutionalisation of cultural capital was the access to physical premises where collections could be housed. The CE had also taken over various buildings in their communities as museums and these operated as foci for community activities and places in which to gather. Quite often this was the old school house, which with declining young populations and centralisation of educational facilities, had been re-purposed as local museums. The museums were used to house the archival collections, but were open to the public with a display of artefacts. This is illustrated in Figure 2. The buildings themselves often became the site of local cafes which provided a community hub where people from across the social spectrum could drop by and new in-migrants (often retirees) could integrate.

\section{*Insert Figure 2 around here*}

The nature of these developments reflects the landscape of living in the Outer Hebrides, whereby outside the main town of Stornoway, the population is sparse and amenities are limited. Hence a number of CE have sought to fill many of the gaps in provision that this brings, consequently extending the role the CE have in different communities. This comes from both a desire to improve the amenities in an area but also represents the need for CE to find other forms of income to support their activities. As the CE member below states, the need to generate income to sustain the CE's activities causes them to move beyond the activities of collecting histories and into other areas:

My lead role at the moment in the Comunn Eachdraidh is looking at ways to widen it to make it sustainable. So that the museum, which I see as very important and the archive, may not generate money in themselves, they will generate massive interest and bring people in and it's looking at things like having a café on the site or something so we can get some money. We'll get some money from the heritage, historical side, in terms of book sales and things like that but only probably enough to justify having done it; we'll break even on them. We're not going to make massive profits on anything in that. (Respondent 5)

With the need to maintain premises for their collections but also with the ambition to expand, in many of their communities the role the CE has moved from museums into areas of local service provision by providing a social centre for diverse groups to meet. Within the context of the Islands, this particularly pertinent and valuable to communities, as in some areas this is the only space in which such activities can take place and people might need to travel many miles to find petrol or milk. At Ravenspoint, for example, the building also contains a thriving publishing company (The Island Book Trust), a hostel, a community shop and were just in the process of constructing a petrol station. In addition they provide Gaelic language courses. This multi-faceted use of space is mirrored at a number of other CE locations too (for example: Kinloch, North Uist, South Uist and Uig), where similar activities and functions have expanded the role the CE has within the community. Whilst in the past, the "ceilidh house" provided a gathering place for events and storytelling in the traditional Gaelic community, some respondents pointed out that the museum had started to take on this function in the modern community.

As well as this CE members have been strongly involved in the move towards the community ownership of land, which is possible under Scottish law, whereby surrounding land is acquired by the local community. CE members have often played a strong role in making these kinds of community 
led initiatives happen (Skerratt, Hall 2011) which is often generated by their strong understanding of local history and the historical vulnerability of land tenure in a crofting system. Therefore although starting with a focus based upon cultural heritage, the activities involved spill out into other things within their communities, giving $\mathrm{CE}$ an even stronger and more central role than an historical association would normally have in the UK. It can also be realised in terms of economic value as the respondent above makes clear.

Although the focus might be primarily on collecting community history, due the cultural and social capital that this produces, it becomes so much more within the locations, offering amenities, employment (both paid and voluntary) and educational opportunities. This is a key component to the way in which all CE groups develop and consequently brings a form of cultural value to their communities that builds on their core activities. This in turn nurtures community ties and guarantees that such archive spaces are active the majority of the time.

\section{Digital gathering}

Digitisation provided new kinds of gathering places for cultural heritage - virtual ones. This is where the work of Ash et al (2016) is most pertinent as the 'digital turn' for the Comainn Eachdraidh follows a process of being 'through', 'produced' and 'of' the digital. By providing a network linking the various $C E$ organisations and a method for linking their various collections, Hebridean Connections took local cultural heritage to a new stage. It forms a new era of the institutionalisation of local cultural capital. Not all communities wanted to form part of Hebridean Connections however, whether or not they digitised their collections, as they were concerned about losing control of their material as it moved into a digital dimension. This is an important factor because digitisation was not seen as a universal positive by all the groups or by members within CE that had decided to contribute to Hebridean Connections.

As in any community, these initiatives are fraught with difficulties but it became apparent that despite the difficulties CE and Hebridean Connections face in this process, it was also creating new relationships of connectedness. This happened in three ways. Firstly, the project has helped 'bridge' gaps between different CE, which created new geographies produced 'through and by the digital' (Ash et al., 2016), whereby the need to collaborate has meant stronger relationships between groups have developed:

I definitely hope to have a greater understanding of the local community. And I suppose through Comunn Eachdraidh, definitely, I will meet more people. Even that day sitting in that room, because I didn't know who half the people were...I suppose l'll get to know who more people are, locally, so that's definitely something that l'll gain from it. (Respondent 1)

The above quote highlights two things about the use of digital technology both how knowledge (for the individual) is through digital activity and how their relationship to the local community is also (re)produced by their participation. Thus, the mixing and meeting with other CE through the training provided by Hebridean Connections has created a space through which stronger connections between communities and individuals can be built. The system itself, and the need to collaborate in the production of digital records, has also meant that much more dialogue between the groups has been produced. This is interesting in itself as Putnam (2000), in his articulation of social capital, suggested that digital technologies were partly at fault for the loss of such relationships. Here, collaboration and participation in the project show something different is taking place, suggesting that digital activities such as these need not be isolating and the very practices that produce digital forms as in themselves reconstituting socio-spatial relationships (Rose, 2105; Ash et al., 2016). 
Secondly, for newcomers to island communities, the ability to help on the project has been a significant 'bridge' into CE groups, allowing 'outsiders' to bond and integrate into pre-existing communities more easily:

Well I'm learning new skills. It's on a very simple level at the moment, just being taught how to create records and now that a bit more time is becoming available, I hope to become a bit more active with the local historical society. So gaining knowledge and contacts.

(Respondent 4)

I don't know, I think if you live in a community you have to give something back to the community. So to me, it's a two-way street; I get lots of knowledge and information about the actual community that I live in and in return I can give something back: data entry is not a complicated job to do. Having done research in my own family history, it's a complicated thing to understand, a lot of the records and things don't make sense or add up but for me, I think it's nice to be part of the local community. (Respondent 1)

As we can see the digitisation of heritage was also a way of generating new kinds of cultural and social capital. It was perhaps this outside view that helped to prompt the institutionalisation of embodied cultural capital which was otherwise locked in the heads and memories of some local community members and in danger of dying with them. People wishing to understand local history or research their ancestry would be referred to particular individuals who might know. Digitisation encouraged the institutionalisation and transmission of embodied knowledge.

The ability to take part in an activity in which you could be helpful to a pre-existing group, by bringing externally acquired skills but not be viewed as in some way 'overbearing', was an opportunity that a variety of participants really benefitted from. Therefore the nature of the voluntary 'digital work' that creating archives like these produces has allowed people to integrate into a community more easily. Here, cultural activity and the ability to participate creates different forms of cultural value for those involved. The community acquires more members who can make a meaningful contribution despite them not having an in-depth knowledge of the locale and those coming in can further develop their sense of connectedness within the community. It also represents how the CE movement is not just indigenous Islanders remembering their past but a vibrant series of communities attracting incomers who bring skills as well as bridging social capital to institutions outside the island.

Thirdly, digitization also fostered another kind of social linking- to the Scottish Diaspora communities. The keen interest in Scottish heritage and in tracing 'one's roots' that is found among Scottish descendants elsewhere provides a new set of users and contributors to the digital platform. These more geographically scattered people could link in to cultural heritage information through the use of Hebridean Connections websites and data bases which provided information about former residents, their fishing boats, marriages and crofts as well as places where they were born and died.

Therefore digitisation was seen as a way in which historical records of value to the communities could be preserved. Crumbling papers, obsolescent tape recordings and fading photos could be preserved, enhanced and given a new life online. This again picks up upon the work of Stiegler (2010) but seeks to extend it too. Stiegler highlights how this form of pedagogical memory work, seeks the transmission of cultural knowledge across generations, only here, through the different and new 'connectivities' being created, the transmission of cultural memory moves beyond generational transmission, to encompass people external to that ancestral relationship. To caveat 
this, to some, this was also seen as a threat to local communities who would thereby lose control to some extent of 'their' historical narratives and property. Additional and contested narratives could arrive from outside the community (for example from Diaspora communities) and materials become submerged in the great global ocean of communications and subsequently re-mashed in unknown ways. This was why some CEs refused to participate in the online platforms created by Hebridean Connections.

\section{Conclusions}

In this paper we have played with several meanings of the term 'gathering' - physical and virtual collecting, meeting and the creation of collective narratives. We have used this to explore the act of collecting and collating archives and materials in order to put stories together and build connections through historical narratives. In developing this we have been able to show how this also leads to a social notion of gathering as a means of linking people into meaningful networks and groups generating social capital and cultural capital. This requires the sustained and ongoing maintenance of physical gathering spaces - such as archives and museums - as well as digital gathering through Hebridean Connections. These become the basis for other kinds of gatherings; it was previously traditional in Island communities to gather in 'ceilidh houses' where customarily cultural knowledge was passed between generations. As this tradition has diminished the CE movement (and by extension Hebridean Connections) have stepped in.

Thus, through the creation of both physical and virtual spaces the continued gathering of knowledge and expertise can be facilitated and shared which otherwise would have been lost. It enabled wider communities, including those from the Diaspora, to access to these materials. However, digitisation of materials through the online platform created by Hebridean Connections also threatened the loss of control of records and memories (see Vincent \& Harrow, 2005). The digital gathering extends this process beyond the Islander communities, as it allows for a variety of materials to be put together showing how new and unforeseen connections can be made possible. This represents the shifting geographies created by digitisation due to the transformation of both memory and objects into data (Rose, 2015). It also generates new and far reaching kinds of exposure that this and subsequent generations can build upon. Central to these processes has been the building of cultural and social capital. Activity and participation has allowed the CE communities to develop different forms of knowledge, skills and expertise. This builds feelings of belonging and collective identity that spreads into the broader community as a whole and facilitates exposure to a wider world. With near entire universal membership (although not all are active members) the CE in Island life is central to formation of local identity, social norms of working together and trust. It enabled a particular narrative of community to be constructed which represented one of cohesion and continuity despite the breaks engendered by incoming communities both in the nineteenth century through crofting and more recently through counter-urbanisation. This in turn represents a significant form of cultural value to the communities involved which helps sustain and reproduce social formation in the Western Isles.

Bourdieu (1986) struggled with the 'conversion' between different kinds of capital. We have been able to show how cultural capital in the form of local knowledge links to social capital in terms of cultural heritage practices and how this helps to bridge and challenge conventional symbolic hierarchies of the kind suggested by Bourdieu. Our argument has been that the activities of the local historical associations references embodied social capital and institutionalises it through the museums and collections. In this way they create cultural value as something intrinsic to a particular community rather than as something created by hegemonic culture. As an example of the local creation of cultural value, it represents a new chapter in how narratives about these communities 
are being constructed in ways that are both inclusionary and exclusionary. This was being done from below and not above as articulated by Bourdieu in his writings. The digitisation of these collections brings new transformations and wider networks of cultural and social capital. We have shown how the value of cultural heritage is generated but also reproduced through these symbolic forms of capital. At this point it becomes more than just a metaphoric way of understanding social relations and converts into a fundamental value for the continued existence of these remote communities.

\section{Acknowledgements}

This research project was supported by the AHRC Cultural Value research programme, award reference AH/L006006/1. We would like to thank Hebridean Connections and the broader Comainn Eachdraidh movement for their collaboration as research partners. We would also like to thank the broader CURIOS team for their assistance and Dr. Cheryl McGeachan for her kinds words of support. Finally, we our greatly indebted to our reviewers for their constructive comments which have greatly strengthened the paper. 


\section{Figures}

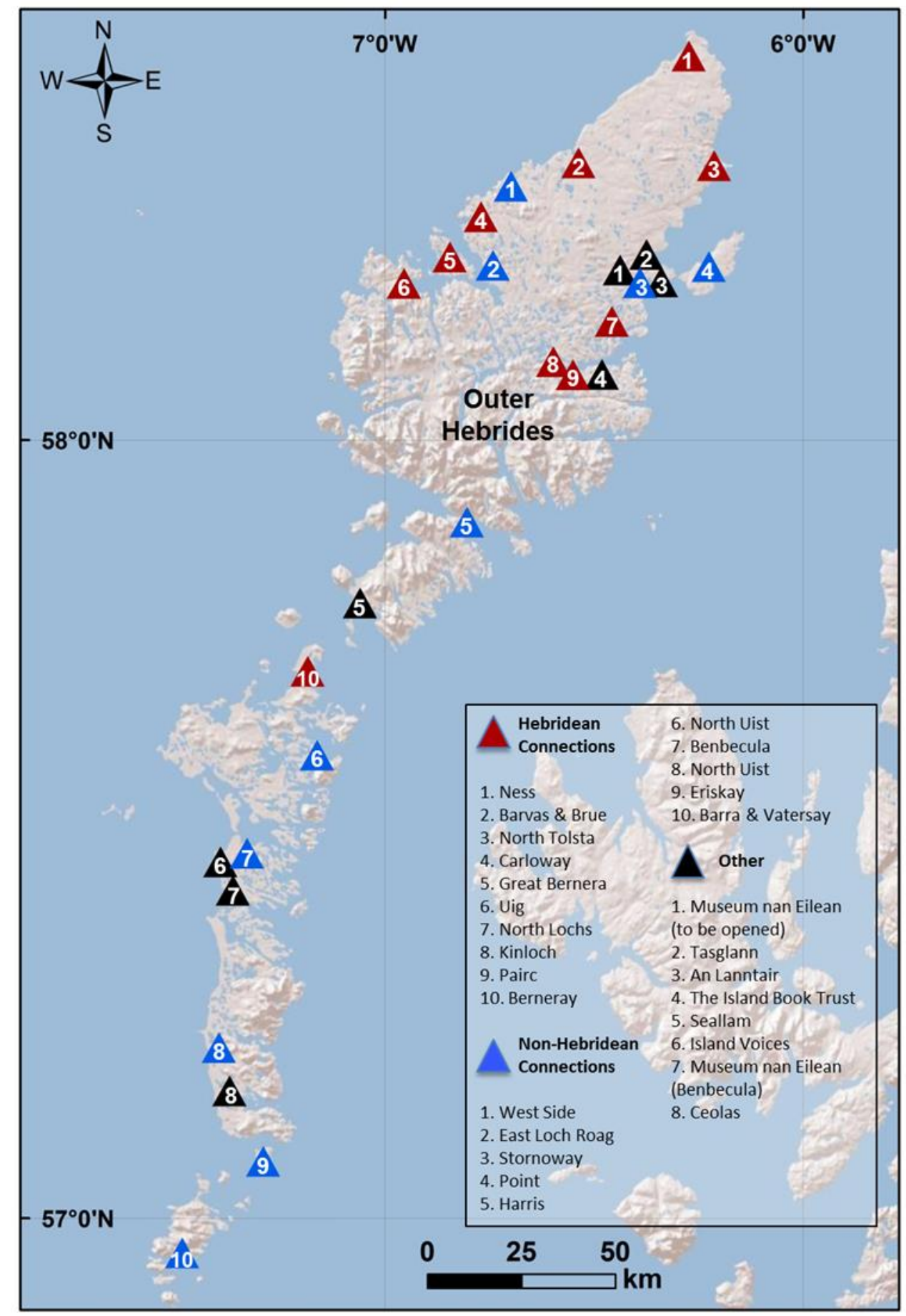

Figure 1-A map of the Western Isles highlighting the different CE groups and their involvement with Hebridean Connections. The map also highlights other cultural actors with the Isles. 


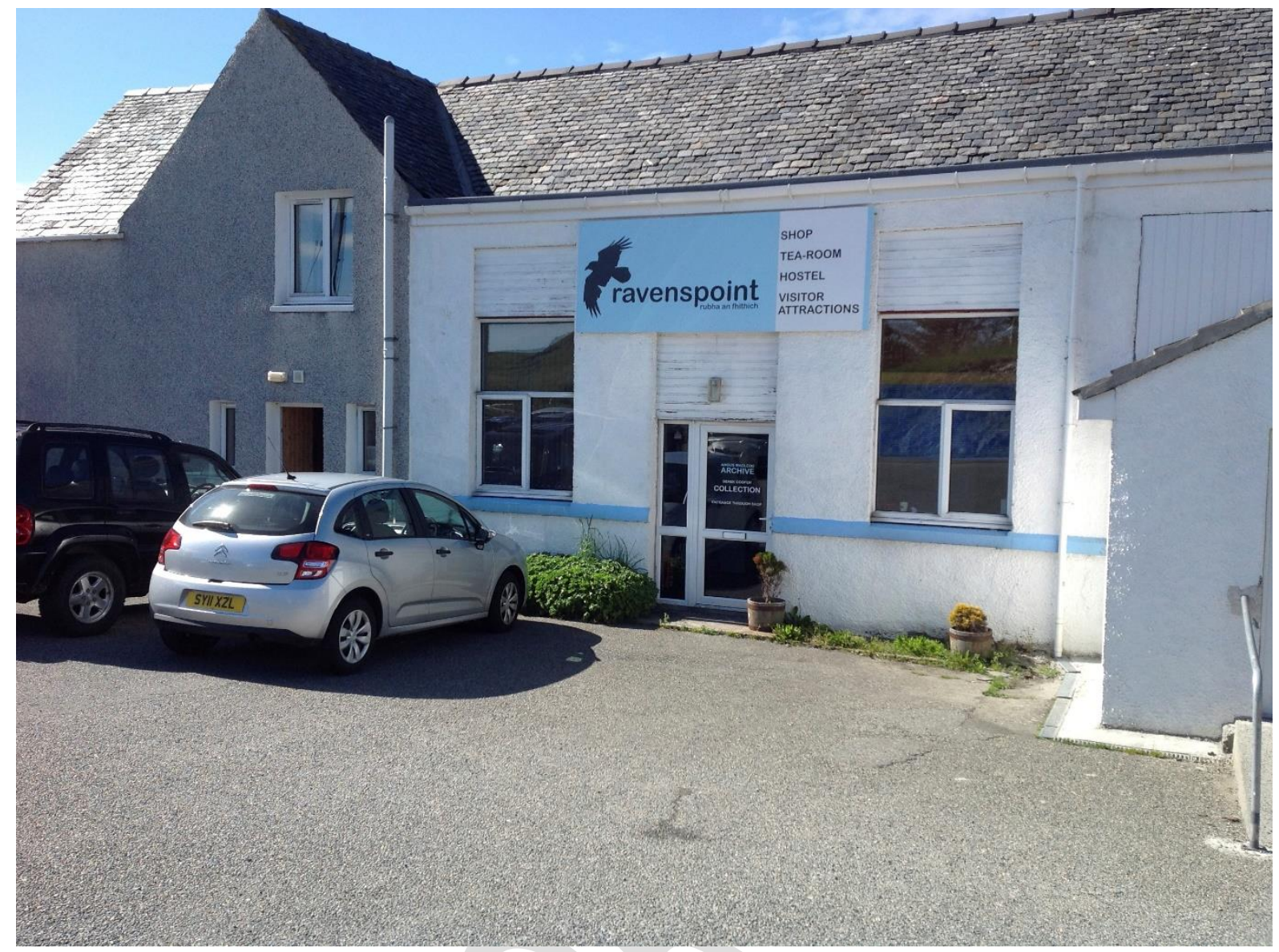

Figure 2 - Ravenspoint Centre and home of Comainn Eachdraidh Pairc. 


\section{References}

Alderman, D. H. \& Inwood, J. (2013). Street Naming and the Politics of Belonging: Spatial Injustices in the Toponymic Commemoration of Martin Luther King Jr. Social \& Cultural Geography, 14(2), 211-233.

Appadurai, A. (1986). The Social Life of Things. Commodities in Cultural Perspective. Cambridge: Cambridge University Press.

Ash, J., Kitchin, R., \& Leszczynski, A. (2016). Digital turn, digital geographies? Progress in Human Geography.

Beel, D., Wallace, C., Webster, G., \& Nguyen, H. (2015). The Geographies of Community History Digital Archives in Rural Scotland. Scottish Geographical Journal, 131(3-4), 201-211.

Beel, D. E., Wallace, C. D., Webster, G., Nguyen, H., Tait, E., Macleod, M., \& Mellish, C. (2017). Cultural resilience: The production of rural community heritage, digital archives and the role of volunteers. Journal of Rural Studies, 54, 459-468.

Bourdieu, P. and Wacquant, L.J.D. (1992). An Introdcution to Reflexive Sociology. Chicago: University of Chicago Press.

Bourdieu, P. (1984). Distinction. London: Routledge \& Kegan Paul.

Bourdieu, P. (1983). Forms of Capital. In: J. RICHARDSON, ed, Handbook of Theory and Research in the Sociology of Education. New York: Greenwood Press.

Cook, I. (1997). Participant observation. In: R. FLOWERDEW and D. MARTIN, eds, Methods in Human Geography. Harlow: Longman.

Cresswell, T. (2011). Value, gleaning and the archive in Maxwell Street, Chicago. Transactions of the Institute of British Geographers, 37(1), 1-13.

Edensor, T., Leslie, D., Millington, S., \& Rantisi, N. M. (2009). Spaces of Vernacular Creativity Rethinking the cultural economy. London: Routledge.

Elwood, S., \& Mitchell, K. (2015). Technology, memory, and collective knowing. Cultural Geographies, 22(1), 147-154.

Eyles, J. and Smith, D.M. (1988). Qualitative Methods in Human Geography. Oxford: Oxford University Press.

Graeber, D. (2001). Towards and Anthropological Theory of Value. Basingstoke: Palgrave.

Hetherington, K. (2006). Capitalism's Eye: Cultural Spaces of the Commodity. London: Routledge.

Holden, J. (2006). Cultural Value and the Crisis of Legitimacy. London: DEMOS.

Hunter, J. (1976). The Making of the Crofting Community. Edinburgh: John Donald. 
Ingold, T. (2000). The Perception of the Environment. London and New York: Routledge.

Jedrej, C. and Nuttall, M., (1996). White Settlers. The Impact of Rural Repopulation in Scotland. London and New York: Routledge.

Kearns, R.A., (2000). Being there: research through observing and participating. In: I. HAY, ed, Qualitative Research Methods in Human Geography. First edn. Oxford: Oxford University Press.

King, L., Stark, J. F., Cooke, P., King, L., Stark, J. F., \& Cooke, P. (2016). Cultural Value Experiencing the Digital World: The Cultural Value of Digital Engagement with Heritage. Heritage \& Society, 9(1), 76-101.

Kinsley, S. (2010) 'Representing 'Things to Come': Feeling the Visions of Future Technologies', Environment and Planning A, 42(11), 2771-90;

Longhurst, R. (2013). Using skype to mother: Bodies, emotions, visuality, and screens. Environment and Planning D: Society and Space, 31(4), 664-679.

Longhurst, R. (2016). Mothering, digital media and emotional geographies in Hamilton, Aotearoa New Zealand. Social \& Cultural Geography, 17(1), 120-139.

Mackay, D. (1996). We did it ourselves : an account of the Western Isles Community Education Project $=$ Sinn Fhein a rinn e $:$ Proisect Muinntir nan Eilean 1977-1992. Bernard van Leer Foundation.

Mackenzie, A. F. D. (2010). Re-stor(y)ing North West Sutherland, Scotland. Scottish Geographical Journal, 126(3), 162-184.

Mackenzie, A.F.D. (2013). Places of Possibility. Property, Nature and Community Land Ownership. Oxford: Wiley-Blackwell.

Mason, R. and Baveystock, Z. (2008). What role can digital heritage play in the re-imaginng of national identities: England and its icons. In: M. ANICO and E. PERALTA, eds, Heritage and Identity: Engagement and Demission in the Contemporary World. London: Routledge, .

Massey, D. (1994). A Global Sense of Place. In Space, Place and Gender. Minnneapolis: University of Minnesota Press.

McGuigan, J. (2004). Rethinking Cultural Policy. Maidenhead: Open University Press.

Meah, A., \& Jackson, P. (2016). Re-imagining the kitchen as a site of memory. Social \& Cultural Geography, 17(4), 511-532.

Miles, A. and Ebrey, J. 2017. The village in the city: participation and cultural value on the urban periphery. Cultural Trends, 26(1), 8-69.

Mulligan, M. (2015). On ambivalence and hope in the restless search for community: How to work with the idea of community in the global age. Sociology, 49(2), 340-355.

Muzaini, H. (2013). Scale politics, vernacular memory and the preservation of the Green Ridge battlefield in Kampar, Malaysia. Social \& Cultural Geography, 14(4), 389-409.

Nora, P. (1989). Between memory and history: Les lieux de Memoire. Representations, 26, 7-24. 
O'Brian, D. (2010). Measuing the value of culture: a report to the Deparment of Culture, Media and Sport. London: DCMS.

Orr, J. (2008). Instrumental or intrinsic? Cultural policy in Scotland since devolution. Cultural Trends, 17(4), 309-316.

Putnam, R.D. (2000). Bowling Alone. The Collapse and Revival of American Community. New York: Simon and Schuster.

Putnam, R.D., Leonardi, R. and Raffaella, N. (1993). Making Democracy Work. Civic Traditions in Modern Italy. Princeton, N.J.: University of Princeton Press.

Robertson, I.J.M. ed, (2012). Heritage from Below. Farnham: Ashgate.

Robertson, M. (2009). Aite Dachaidh: re-connecting people with place - Island landscapes and the intangible heritage. International Journal of Heritage Studies, 15(2-3), 153-162.

Rose-Redwood, R. S. (2008). From number to name: symbolic capital, places of memory and the politics of street renaming in New York City. Social \& Cultural Geography, 9, 431-452.

Rose, G. (2015). Rethinking the geographies of cultural "objects" through digital technologies: Interface, network and friction. Progress in Human Geography, 40(3), 334-351.

Rose, G. (2016). Cultural geography going viral. Social \& Cultural Geography, 17(6), 763-767.

Rose, M. (2012). Dwelling as marking and claiming. Environment and Planning D: Society and Space, $30,757-771$.

Samuel, R. ed, (1981). People's History and Socialist Theory. London: Routledge and Kegan Paul.

Skeggs, B. (2014). Values beyond value? Is anything beyond the logic of capital? British Journal of Sociology, 65(1), 1-20.

Skerratt, S. and Hall, C. (2011). Community ownership of physical assets: Challenges, complexities and implications. Local Economy, 29(3), 170-181.

Smith, M. (2010). Arts funidng in a cooler climate: Subsidy, commerce and the mixed economy of culture in the UK. London: Arts and Business.

Stevens, M., Flinn, A. and Shepherd, E. (2010). New frameworks for community engagement in the archive sector: from handing over to handing on. International Journal of Heritage Studies, 16(1-2), 59-76.

Stiegler, B. (2010). Taking Care of Youth and the Generations. Stanford: Stanford University Press.

Tait, E., Macleod, M., Beel, D., Wallace, C., Melish, C., \& Taylor, S. (2013). Linking to the past: an analysis of community digital heritage initiatives. Aslib Proceedings, 65(6), $564-580$.

Thompson, L., \& Cupples, J. (2008). Seen and not heard? Text messaging and digital sociality. Social \& Cultural Geography, 9(1), 95-108.

Vincent, J., \& Harrow, J. (2005). Comparing Thistles and Roses: The Application of Governmental- 
Voluntary Sector Relations Theory to Scotland and England. VOLUNTAS: International Journal of Voluntary and Nonprofit Organizations, 16(4), 375-395.

Wallace, C., Vincent, K., Luguzan, C., Townsend, L., \& Beel, D. (2016). Information technology and social cohesion: A tale of two villages. Journal of Rural Studies, 54, 426-434.

Waterton, E., \& Smith, L. (2010.) The recognition and misrecognition of community heritage. International Journal of Heritage Studies, 16(1-2), 4-15.

Williams, R. (2010). Keywords: A Vocabulary of Culture and Society. London: Fontana.

Wilson, M. (2012). 'Location-Based Services, Conspicuous Mobility, and the Location-Aware Future Location Aware Future', Geoforum, 43(6), 1266- 75. 